\title{
Long-term Orientation, Perceived Consumer Effectiveness, and Environmentally Conscious Consumer Behavior: The Case of Turkey
}

\author{
Misra C. Gul ${ }^{1}$ \\ ${ }^{1}$ College of Administrative Sciences and Economics, Isik University, Istanbul, Turkey \\ Correspondence: Misra C. Gul, College of Administrative Sciences and Economics, Isik University, Sile, \\ Istanbul, Turkey. Tel: 90-216-528-7209. E-mail: misragul@isikun.edu.tr
}

\author{
Received: April 10, $2013 \quad$ Accepted: July 18, 2013 Online Published: August 6, 2013 \\ doi:10.5539/ijms.v5n5p24 URL: http://dx.doi.org/10.5539/ijms.v5n5p24
}

\begin{abstract}
This paper analyzes the impact of long-term orientation and perceived consumer effectiveness on environmentally/ecologically conscious consumer behavior in the context of Turkey. Turkey is a collectivist, high-context culture of significant geo-political importance with unique socio-cultural traits. The population is young and natural resources are rich. In Turkey, environmental consciousness is a relatively less internalized concept to which people are just recently beginning to adjust. All of this makes Turkey an interesting market to study the environmentally conscious consumer behavior (ECCB) construct. Looking at the impact of long-term orientation on ECCB is also one of the important contributions of this paper since environmental consciousness requires a long-term view of the world around us. Building upon the adaptation and extension of past research in the area, data are collected from 97 respondents, 80 per cent of whom are undergraduate college students, and analyzed through commonly used statistical methods. The measures used are similar to those used in previous studies. Environmentally conscious consumer behavior measure is adapted from Roberts (1996b) and McCarty and Shrum (1994). Roberts' (1996b) perceived consumer effectiveness measure is used in the study. Long-term orientation scale is adapted from Bearden, Money and Nevins (2006).
\end{abstract}

Keywords: environmentally conscious consumer behavior, green marketing, perceived consumer effectiveness, long-term orientation, Turkey

\section{Introduction}

For the last few decades, concepts of environmentalism and environmental concern have been on the rise. (Chan and Lau, 2000; Han, Hsu, and Lee, 2009). Customers have become more environmentally conscious and many consumers put forth a significant effort to buy eco-friendly products and services from eco-friendly firms (Roberts, 1996; Kalafatis, Pollard, East, and Tsogas, 1999). Many researchers have looked at numerous drivers of environmentally conscious consumer behavior (ECCB) in an attempt to understand the psychological, economic, cultural, and other influencers of the phenomenon (Roberts, 1996; Ger, 1999; Sarigollu, 2009). In a similar effort, this study aims to shed light onto the effects of long-term orientation and perceived customer effectiveness together and independently on environmentally conscious consumer behavior in Turkey, an emerging and culturally interesting market. Turkey is a collectivist, high-context culture of significant geo-political importance with unique socio-cultural traits where environmental consciousness is a relatively less internalized concept to which people are just recently beginning to adjust.

\section{Background Literature}

\subsection{Environmentally Conscious Consumer Behavior (ECCB)}

Environmentally conscious consumer behavior has been a popular topic for research in the marketing academia. Various aspects of sensitivity to environmental protection have been studied in the literature. The 1990s, for example, were named the "decade of the environment" (Drumwright, 1994), as social and environmental concerns had grown to be perceived as more important. Today, environmental concerns have become more vivid and awareness has increased. Kotler (2003) predicted that "societal marketing concept" would be one of the key elements of firms' marketing strategies, and this prediction has proven to be correct. Even though environmental concerns have increased over the past twenty years, environmentally friendly brands have received significantly low levels of market share (Kalafatis et al., 1999). Kalafatis et al. (1999) states and cites two explanations for 
this discrepancy. First explanation is that economic considerations are more important than environmental concerns when it comes to purchase behavior, and the second is the multifaceted nature of environmental concern influencing some behaviors and not others.

The concept of "environmentally conscious consumer" has been defined in the literature in a variety of ways. This study adheres to the Roberts (1996) definition that states that a consumer is to be considered environmentally conscious if they purchase goods and services which they believe to have a positive or a less negative impact on the environment.

Meffert and Kirchgeorg (1993) suggest that environmentally conscious consumer behavior might occur in a number of ways. They list five types of environmentally conscious consumer behavior: Reducing the consumption of traditional goods, adjusting demand - purchasing eco-friendly products instead of traditional ones, consuming environmentally efficient goods, participation in recycling and separate waste collection, and taking part in environmentally conscious complaints or protests.

\subsection{Perceived Consumer Effectiveness (PCE)}

Many studies have analyzed the premise that consumers' attitudes and responses to environmental concerns are directly related to their belief that they can make a positive difference in the results of those concerns. This belief is termed as perceived consumer effectiveness (PCE). PCE has consistently been found positively correlated to ECCB (Aaker and Bagozzi, 1982; Roberts and Bacon, 1997).

Cleveland, Kalamas, and Laroche (2005) found that even if consumers are concerned about the environment, they may not act on this concern without a sense of empowerment. This finding was stated as a third possible explanation of why environmental concerns may not translate into behavior, in addition to the two explanations that Kalafatis et al. (1999) has suggested. Compared to other personality factors such as optimism and safety, personal control has been proven to be the strongest predictor of green behavior (Allen and Ferrand, 1999). As a result of these arguments, this research proposes that perceived consumer effectiveness has a positive significant impact on ECCB.

\subsection{Long-Term Orientation (LTO)}

Culture as one of the important influencers of environmentally conscious consumer behavior has also found its place in the literature (Ger, 1999; Joreiman, Van Lange, and Van Vugt, 2004; Sarigollu, 2009). Ger's (1999) qualitative study with consumers from different social classes in Turkey revealed that Turkish people assign a reduced importance to the protection of the environment. Even though most consumers are knowledgeable about environmental issues, they are most of the time not sensitive to the environmental effect of their actions (Ger, 1999). In emerging economies in general, some researchers have found limited sensitivity to environmental issues as a consequence of poor knowledge, high-costs, and skepticism associated with ecologically friendly products. Even when awareness existed, environmental sensitivity was limited (Carrete et al., 2012). Carrete et al. (2012) also found that Mexican consumers did not engage in much green behavior and when they did, the key motivator was family well being rather than environmental sensitivity.

Hofstede (1980) states that long-term orientation refers to the prospects perceived by an individual that a society will be in a position to overcome its problems over time. Bearden, Money, and Nevins (2006) define long-term orientation as "the cultural value of viewing time holistically, valueing both past and the future rather than deeming actions important only in their effects in the here and now or the short term". In a study in Sri Lanka, Samarasinghe (2012) found that both collectivism and long-term orientation were good predictors for environmental attitude formation. In addition, significant differences were found between collectivist versus individualistic, past-oriented versus future-oriented cultures in terms of environmental attitudes. Sarigollu (2009) also found that long-term oriented people are more likely to develop values and attitudes pertaining to the protection of the natural environment. Based on the discussion above, we propose that long-term orientation has a positive significant impact on ECCB.

\section{Method}

Data for this study are collected through a self-administered online survey purposively sent mainly to undergraduate students at a university Istanbul. Most of the students filled out the survey in return for extra credit for their classes. Building upon the adaptation and extension of past research in the area, data are collected from 97 respondents, 78 per cent of whom are undergraduate college students. Non-student data are collected for basic comparison purposes. The measures used are similar to those used in previous studies. Environmentally conscious consumer behavior and perceived consumer effectiveness measures are adapted from Roberts (1996b) and McCarty and Shrum (1994). Long-term orientation scale is adapted from Bearden, Money and Nevins 
(2006). Items that are irrelevant to the Turkish context are eliminated. The survey consists of 34 items rated on a five point Likert type scale. In addition, some demographic information on respondents is collected. Original scale items in English were used instead of translation to avoid loss of meaning since all respondents are fluent in English. The respondents are either attending or have graduated from universities in which the medium of education is English. The questionnaire can be found in the Appendix.

Table 1 summarizes the sample characteristics.

Table 1. Sample characteristics

\begin{tabular}{llll}
\hline Gender & Age & Education/Occupation & $\begin{array}{l}\text { Class Specification at } \\
\text { School }\end{array}$ \\
\hline Female: $54 \%$ & $18-23: 78 \%$ & $78 \%$ Undergraduate Students & Freshman: $8 \%$ \\
Male: $46 \%$ & $28-43: 22 \%$ & $22 \%$ Professionals with & Sophomore: $11 \%$ \\
& & Graduate Degrees & Junior: $39 \%$ \\
& & & Senior: $20 \%$ \\
& & & Not Applicable: $22 \%$ \\
\hline
\end{tabular}

\section{Results}

Data are analyzed through descriptive statistics, Pearson's correlations, multiple regression analysis, and independent t-tests for mean comparisons. Scale reliability was assessed for all measures used in the study before the analysis. ECCB, PCE, and LTO variables are constructed by taking the average of scale items per respondent for each scale.

Reliability analysis was carried out for the measures used in the study. The ECCB and LTO measures have Cronbach's alpha values of .889 and .735 , respectively, well above the acceptable threshold level of .60 (Nunnally, 1970). PCE measure, however, had a below the threshold Cronbach's alpha value, which improved after deleting the second item in this measure "When I buy products, I try to consider how my use of them will affect the environment and other consumers". There existed no conceptual problem with the removal of this item from the measure. The improved reliability statistic is .613.

Table 2. Means, standard deviations and Pearson's correlations

\begin{tabular}{lllllll}
\hline & Mean & Std. Deviation & ECCB & PCE & LTO \\
\cline { 2 - 7 } ECCB & 3.27 & .573 & 1 & & \\
PCE & 3.55 & .818 & -.131 & 1 & \\
LTO & 3.87 & .535 & $.319^{* *}$ & .041 & 1 \\
\hline
\end{tabular}

$* * \mathrm{p}<.01$ level $(2$ tailed)

Descriptive statistics and Pearson's correlations for the constructs can be found in Table 2. In terms of ECCB, a mean of 3.27 shows that participants are somewhat in the middle. This means that they are neither reluctant nor keen on engaging in environmentally conscious consumer behavior. This result is inline with previous studies in similar markets. PCE construct has a mean of 3.55, which suggests that participants have some level of belief that they can be effective and make a difference with their environmentally conscious behavior. LTO has a mean of 3.87, which suggests a relatively high level of long-term orientation, which can be expected from a collectivist culture like Turkey.

Correlation results are interesting. As can be seen in Table 2, the only significant correlation exists between ECCB and LTO. The ECCB-LTO correlation is not surprising. However, ECCB and PCE do not have a significant correlation, even though a significant correlation would have been theoretically expected between these constructs. Data are analyzed further using multiple regression analysis. 
Table 3. Findings from multiple regression analysis

\begin{tabular}{lll}
\hline Variable & Regression Coefficient & Significance \\
\hline Constant & 4,937 & .000 \\
PCE & -.144 & .139 \\
LTO & .325 & .001 \\
\hline
\end{tabular}

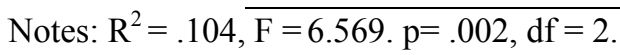

When multiple regression analysis results are reviewed (see Table 3), it can be seen that the model has significant exploratory power. LTO has a significant positive impact on ECCB, whereas PCE impact on ECCB is insignificant. This finding is consistent with findings from correlation analysis.

In addition to the main findings, data are analyzed for gender comparisons and comparisons between the student and professional participants of the study. Independent t-tests are run, and no significant difference is found for either categorization. When descriptive statistics are compared for women and men in the sample, the most visible difference is for ECCB. Women had a higher ECCB mean score of 3.40 compared to the men's score of 3.11. When student and professional groups are compared in terms of descriptive statistics, the biggest difference is in PCE. The professional group has a perceived consumer effectiveness mean score of 3.83. PCE mean score for the student group is 3.48 .

\section{Discussion and Concluding Remarks}

This research started out to extend and expand previous literature on environmentally conscious consumer behavior and its determinants, focusing on Turkey, an emerging market with collectivist culture between the East and the West. The study has brought about some interesting findings that managers should take into account. According to the findings, long-term orientation has a positive significant impact on environmentally conscious consumer behavior. This is not only inline with our proposition based on theory, but also makes sense since the outcomes of environmentally protective and sensitive behavior can mostly be observed in the long-term rather than the time period the behavior takes place.

Perceived customer effectiveness, however, does not a have significant impact on ECCB. This contradicts our proposition and expectations. This contradiction may be due to a number of reasons. First, participants of the study who have or about the have at least university degrees may have a general sense of power that makes them believe that their actions are effective, period, in any area. Consequently, this belief may not necessarily result in a causal relationship between PCE and ECCB per se. Second, this finding may be as a result of participants' belief that ECCB should or should not take place irrespective of perceived effectiveness.

Gender comparisons have not shown any significant differences between men and women with respect to ECCB. However, women's ECCB mean score is slightly higher than that of men's, which can be attributed to women's more nurturing and sensitive approach to phenomena around them in general. Likewise, no significant differences are found between the student and professional groups. Professionals' PCE mean score is higher than that of students', which can be due to the fact that they are more established and have a higher sense of power and influence.

There are a few limitations to this study besides its contributions. Even though the sample is a purposive sample meeting the minimum sample size requirements for the analysis methods used, sample characteristics are somewhat uniform. A more heterogeneous sample would allow for a better comparison among different categorical groups.

Further research can be directed towards conducting the same study with a different sample. In addition, various other cultural aspects and their influence on ECCB may be researched. This paper focuses on the Turkish market. Other markets similar to or different from Turkey may be studied.

\section{References}

Aaker, D. A., \& Bagozzi, R. P. (1982). Attitudes toward public policy alternatives to reduce air pollution. Journal of Marketing, 1, 85-94.

Allen, J. B., \& Ferrand, J. L. (1999). Environmental locus of control, sympathy, and pro-environmental behavior a test of Geller's actively caring hypothesis. Environment and Behavior, 31(3), 338-53. http://dx.doi.org/10.1177/00139169921972137

Bearden, W. O., Money, R. B., \& Nevins, J. L. (2006). A Measure of Long-term Orientation: Development and 
Validation. Journal of the Academy of Marketing Science, 34(3), 456-467. http://dx.doi.org/10.1177/0092070306286706

Carrete, L., Castano, R., Felix, R., Centeno, R., \& Gonzales, E. (2012). Green consumer behavior in an emerging economy: confusion, credibility, and compatibility. Journal of Consumer Marketing, 29(7), 470-481. http://dx.doi.org/10.1108/07363761211274983

Chan, R. Y. K., \& Lau, L. B. Y. (2000). Antecedents of green purchases: a survey in China. Journal of Consumer Marketing, 17(4), 338-57. http://dx.doi.org/10.1108/07363760010335358

Cleveland, M., Kalamas, M., \& Laroche, M. (2005). Shades of green: Linking environmental locus of control and pro-environmental behaviours. The Journal of Consumer Marketing, 22(4-5), 198-213. http://dx.doi.org/10.1108/07363760510605317

Ger, G. (1999). Experiential meanings of consumption and sustainability in Turkey. In Arnould, E. J., \& Scott, L. M. (Eds.), Advances in Consumer Research (pp. 276-80). Provo, UT: Association for Consumer Research.

Han, H. L. T., \& Lee, J. S. (2009). Empirical investigation of the roles of attitudes toward green behaviors, overall image, gender, and age in hotel customers' eco-friendly decision-making process. International Journal of Hospitality Management, 28, 519-528. http://dx.doi.org/10.1016/j.ijhm.2009.02.004

Hofstede, G. (1980). Culture's Consequences: International Differences in Work-Related Value. Beverly Hills, CA: Sage.

Joreiman, J. A., Van Lange, P. A. M., \& Van Vugt, M. (2004). Who cares about the environmental impact of cars: Those with and eye toward the future. Environment and Behavior, 36, 187-206. http://dx.doi.org/10.1177/0013916503251476

Kalafatis, S. P., Pollard, M., East, R., \& Tsogas, M. H. (1999). Green marketing and Ajzen's theory of planned behavior: a cross-market examination. Journal of International Consumer Marketing, 16(5), 441-60. http://dx.doi.org/10.1108/07363769910289550

Kotler, P. (2003). Marketing Management (11th ed.). Upper Saddle River, NJ: Prentice Hall.

McCarty, J. A., \& Shrum, L. J. (1994). The recycling of solid wastes: personal values, value orientations, and attitudes about recycling as antecedents of recycling behaviors. Journal of Business Research, 30, 53-63. http://dx.doi.org/10.1016/0148-2963(94)90068-X

Meffer, H., \& Kirchgeorg, M. (1993). Marktorientiertes Umweltmanagement. Grundlagen und Fallstudien. Stuttgart: Schäffer Verlag.

Nunnally, J. C. (1970). Introduction to psychological measurement. New York, NY: McGraw-Hill.

Roberts, J. A. (1996). Green consumers in the 1990s: profile and implications for advertising. Journal of Business Research, 36(3), 217-31. http://dx.doi.org/10.1016/0148-2963(95)00150-6

Roberts, J. A., \& Bacon, D. R. (1997). Exploring the subtle relationships between environmental concern and ecologically conscious consumer behavior. Journal of Business Research, 40(1), 79-89. http://dx.doi.org/10.1016/S0148-2963(96)00280-9

Samarasinghe, R. (2012). The Influence of Cultural Values and Environmental Attitudes on Green Consumer Behaviour. International Journal of Behavioral Science, 7(1), 83-98.

Sarigollu, E. (2009). A Cross-Country Exploration of Environmental Attitudes. Environment and Behavior, 41(3), 365-386. http://dx.doi.org/10.1177/0013916507313920

Straughan, R. D., \& Roberts, J. A. (1999). Environmental segmentation alternatives: a look at green consumer behavior in the new millennium. Journal of Consumer Marketing, 16(6), 558-575. http://dx.doi.org/10.1108/07363769910297506

Yeonshin, K., \& Sejung, M. D. (2005). Antecedents of Green Purchase Behavior: An Examination of Collectivism, Environmental Concern, and PCE. In Arnould, E. J., \& Scott, L. M. (Eds.), Advances in Consumer Research (pp. 592-599). Provo, UT: Association for Consumer Research. 


\section{Appendix}

Environmentally Conscious Consumer Behavior Questionnaire

\begin{tabular}{|c|c|c|c|c|c|}
\hline 1. Please rate the following statements. & $\begin{array}{l}\text { Never } \\
\text { True }\end{array}$ & $\begin{array}{l}\text { Usually } \\
\text { Not True }\end{array}$ & $\begin{array}{l}\text { Occasionally } \\
\text { True }\end{array}$ & $\begin{array}{l}\text { Usually } \\
\text { True }\end{array}$ & Always \\
\hline
\end{tabular}

To save energy, I drive my car as little as possible.

I normally make a conscious effort to limit my use of products that are made of or use scarce(limited)

resources

I will not buy products which have excessive packaging.

When there is a choice, I always choose that product which causes the least amount of pollution.

I have tried very hard to reduce the amount of electricity I use.

If I understand the potential damage to the environment that some products can cause, I do not purchase these products.

I have switched products for ecological reasons. I use a recycling center or in some way recycle some of my household waste.

I make every effort to buy paper products made from recycled paper.

\begin{tabular}{llllll}
\hline 2. Please rate the following statements. & Never & Usually & Occasionally & Usually & Always \\
& True & Not True & True & True & True \\
\hline
\end{tabular}

I have purchased products because they cause less pollution.

I have replaced light bulbs(lamps) in my home with those of smaller wattage so that I will conserve on the electricity I use.

I have convinced members of my family or friends not to buy some products which are harmful to the environment.

I use a recycling center or in some way recycle some of my household trash/waste.

When I purchase products, I always make a conscious effort to buy those products that are low in pollutants.

When I have a choice between two equal products, I always purchase the one which is less harmful to other people and the environment.

I will not buy a product if the company that sells it is ecologically irresponsible.

I have purchased light bulbs (lamps) that were more expensive but saved energy.

I try only to buy products that can be recycled. To reduce our reliance on foreign oil, I drive my car as little as possible.

I usually purchase the lowest priced product, regardless of its impact on society.

I do not buy household products that harm the environment.

I buy high efficiency light bulbs(lamps) to save energy. 


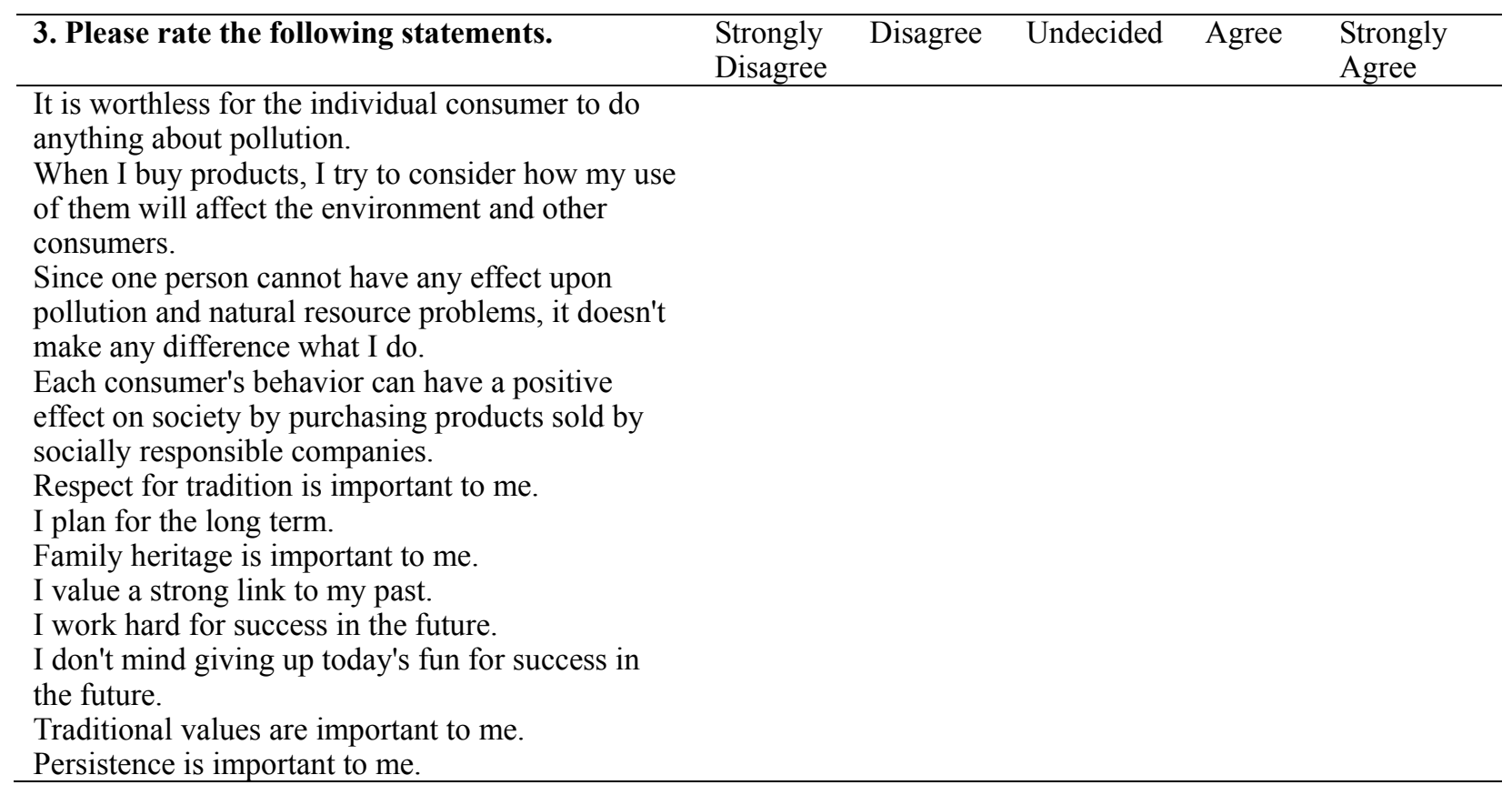

\section{Gender: Male Female}

\section{Classification at School. Choose Not Applicable if you are not a student.}

Freshman

Sophomore

Junior

Senior

Graduate

Not Applicable

\section{Please enter the information indicated below.}

First and Last Name:

Email Address:

City:

\section{Copyrights}

Copyright for this article is retained by the author(s), with first publication rights granted to the journal.

This is an open-access article distributed under the terms and conditions of the Creative Commons Attribution license (http://creativecommons.org/licenses/by/3.0/). 